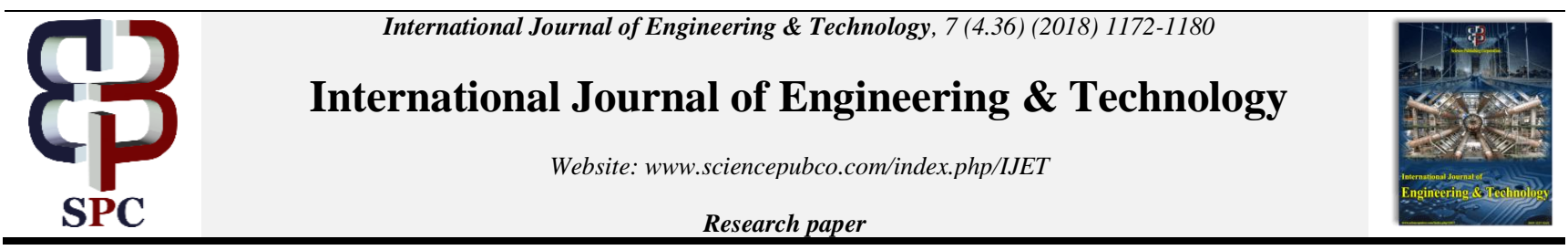

\title{
Solar PV Policy, Barriers and Proposed Solution for Technical Barriers in Thailand
}

\author{
Rongrit Chatthaworn *, Pikkanate Angaphiwatchawal * ,Surachai Chaitusaney *a \\ *Department of Electrical Engineering, Faculty of Engineering,
}

\begin{abstract}
This paper presents solar PV history in Thailand consisting of installation target, incentive schemes, procurements and barriers for supporting the coming of solar PV. For the barrier viewpoint, one of the most significant barriers is the technical power system problem; especially, voltage violation and system loss increase when high capacity of solar PV is installed in the system. Therefore, electric utilities usually determine the capacity limitation criterion of solar PV for each electrical feeder which can delay the growth of solar PV installation. Consequently, this paper presents the method to solve this barrier in order to maximize the installation of solar PV in Thailand. The method is based on the construction of typical distribution feeders with various levels of solar PV penetration and locations. The three scenarios based on solar PV locations: clustered near the beginning of feeder, clustered near the middle of feeder, and clustered near the end of feeder are simulated. The considered constraints are voltage limitation and system loss. The modified distribution system is used to test the proposed method which is simulated by DIgSILENT PowerFactory software. The results show that the proposed method provides the solution that can support more solar PV installation than capacity limitation criterion determined by distribution utilities.
\end{abstract}

Keywords: Capacity limitation, Solar PV incentive schemes, Solar PV maximization, Solar PV policy, Solar PV technical barriers

\section{Introduction}

In order to understand the barriers for supporting solar PV in Thailand, this section explains the solar PV policy, target, incentive scheme, and barriers to deployment of solar PV. Because increasing reliance on natural gas is now almost $70 \%$ of Thailand power generation [1]. Energy security remains a major concern. However, supplementing natural gas power plants will neither always increase energy security nor ensure long-term sustainability. Solar PV is considered not only as a clean energy option but also an empowering tool to reduce Thailand's reliance on fossil fuels and to enable more consumers' participation in electricity generation.

To support the use of solar PV for electricity generation, Thailand's latest Alternative Energy Development Plan 20152036 (AEDP 2015) which is created by Department of Alternative Energy Development and Efficiency (DEDE), Thailand Ministry of Energy, has set the target to increase the share of renewable energy for electricity generation to $20.11 \%$ of total electrical energy demand by 2036 [2]. For solar PV, the target has been set to reach an installed capacity of 6,000 MW by 2036. According to the latest figures announced by Energy Regulatory Commission of Thailand (ERC), the total installed capacity of solar PV has reached 2,761 MW, of which are 2,631 MW of free-field installations (solar farms) and $130 \mathrm{MW}$ of solar rooftops [3].

For incentive scheme or financial support for solar PV producers, there are two schemes from past to present. The first scheme is called "Adder" which is the base electricity rate plus the adder rate. The adder rate has depended on renewable energy types and has been given to the power producers for the first 7 years. Another scheme is called "Feed-in Tariffs (FiTs)" which is the fixed rate for the whole life time of renewable energy project. The outcomes from these supports were very pleasant because total installed capacity of solar PV has been rapidly increased. However, there are many barriers to solar PV growth. For example, high initial cost of solar PV modules, policy uncertainty, and technical barriers. Among all barriers, technical barriers are most important as it prevents the growth of solar PV 
accounting approximately $40 \%$ of total preventions from all barriers. Therefore, this paper mainly focuses on the technical barriers and proposes the associated solution.

The main technical impacts of large scale PV generations on power grid are voltage violation, current limit, power quality, system loss, power factor correction, power balancing, reliability, and protection of the system [4]. Solar PV generation impacts can be steady state or dynamic in nature [5]. These impacts vary in severity as a function of the level of penetration and location of solar PV [6]. Consequently, electric utilities typically determine the capacity limitation criterion for solar PV installation in their systems. However, this experience should not be used as a basis for judging future usefulness of solar PV in Thailand. The distributed solar PV or residential solar PV can offer great benefits in term of peak demand reduction and the postponement of investment in generation, transmission, and distribution facilities, etc.

Distribution electric utilities control the penetration of solar PV by determining the capacity limitation in their grid code. This limitation is calculated from average minimum demand of all feeders in order to avoid reverse power flow. However, it is not proper to apply for all feeders, the minimum demands of some feeders are higher than the average minimum demand; therefore, these feeders have higher capacity for accommodating solar PV. Moreover, this capacity limitation is determined without the consideration of solar PV location. Some feeders can host more amounts of solar PV than the amounts determined in utilities grid code if solar PV is installed at proper locations. Consequently, this paper proposes the method to solve this limitation in order to maximize the level of solar PV in Thailand. The proposed method is based on the classification of typical distribution feeders with various levels of solar PV penetration and locations. The three scenarios based on location: clustered near the beginning of feeder, clustered near the middle of feeder, and clustered near the end of feeder are simulated. The amount of solar PV is maximized while the considered constraints are voltage limitation and system loss.

The remaining part of this paper is organized as follows. The renewable energy policy and status in Thailand is firstly presented in Section 2. The Barriers against solar PV support are presented in Section 3. The present solution for solving technical barriers is explained in Section 4. In Section 5, the method for supporting solar PV is proposed and the simulation results are shown in Section 6. Finally, the conclusion is drawn in Section 7.

\section{Solar PV Policy and Status in Thailand}

Thailand electricity demand has been continuously increasing. The total electricity energy consumption in 2016 was 197,891 GWh and the peak electricity power demand was 30,972.7 MW. Around $63 \%$ of the installed capacity is based on natural gas, while the rest comes from coal $(\sim 18 \%)$, hydro $(\sim 3 \%)$, import $(\sim 8 \%)$ and renewable energy ( $\sim 8 \%)$ [7]. Thailand government recognizes the risk of depending on much natural gas. Therefore, the targets for energy efficiency and renewable energy for electricity production have been set. According to the AEDP 2015, Thailand has aimed to achieve $30 \%$ of final energy consumption using renewable energy sources by 2036. For electricity, $20.11 \%$ of energy consumption has been supplied

\footnotetext{
a) Correspondence to : Assistant professor Dr. Surachai

Chaitusaney.

E-mail: surachai.c@chula.ac.th

*Department of Electrical Engineering, Faculty of Engineering,
}

from renewable energy, which is equal to the total installed capacity of 19,684.4 MW (including hydro power capacity). For solar PV, the target has been set to reach an installed capacity of 6,000 MW by 2036 .

Incentive scheme is the mechanism that has been designed to drive the growth of solar PV in Thailand. Since 2007, two incentive schemes have been put in place to support the growth of solar PV. The first incentive scheme which is called Adder program was implemented in 2007. The Adder program consists of a normal tariff (ranged from 3.06-3.17 Thai Baht $/ \mathrm{kWh}$ ) plus a premium. The premium given for solar PV was set at 8 Thai Baht $/ \mathrm{kWh}$ during 2007-2010. Therefore, the total tariff paid was between 11.06-11.17 Thai Baht $/ \mathrm{kWh}(0.339-0.342 \mathrm{USD} / \mathrm{kWh}$ at exchange rate $=32.66$ Thai Baht/USD) on December 2017 . However, the adder has been reduced to 6.50 Thai Baht $/ \mathrm{kWh}$ for

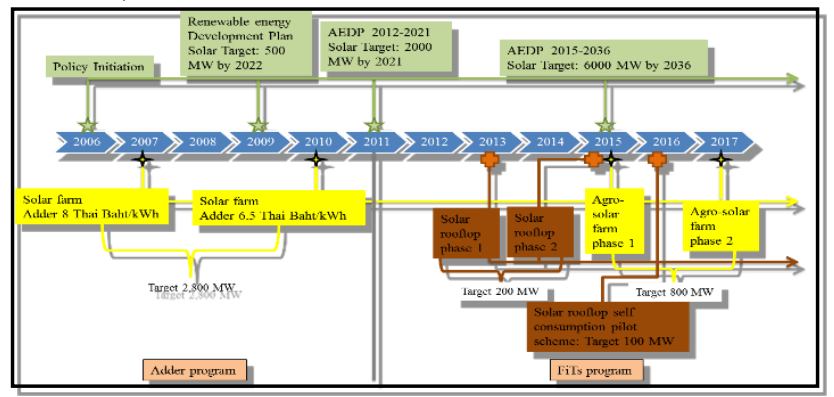

Fig. 2 Timeline for

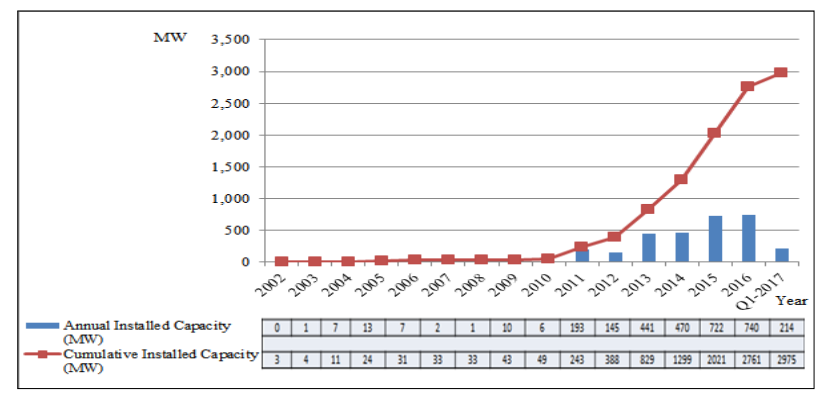

Fig. 1 The growth of Thailand's solar PV installed capacity $[3,8]$

Table 1 FiTs rates for rooftop solar PV approved by NEPC 2013

\begin{tabular}{|c|c|c|}
\hline Scale & $\begin{array}{l}\text { FiTs Rate } \\
\text { (Thai } \\
\text { Baht/kWh) }\end{array}$ & Quota \\
\hline $0-10 \mathrm{~kW}$ & 6.96 & $\begin{array}{c}100 \mathrm{MW} \text { (only about } 30 \mathrm{MW} \text { was } \\
\text { subscribed }\end{array}$ \\
\hline$>10-250 \mathrm{~kW}$ & 6.55 & \multirow[b]{2}{*}{$100 \mathrm{MW}$} \\
\hline $\begin{array}{l}>250-1,000 \\
\mathrm{~kW}\end{array}$ & 6.16 & \\
\hline
\end{tabular}

all projects that were not approved as of 28 June 2010, and the Adder program for solar PV was closed in June 2010. The Adder program had been successful for stimulating renewable energy investment, resulting in continuous growth of solar PV as shown in Fig. 1.

The second incentive scheme is called FiTs. After the suspension of solar PV support between 2010 and 2013, the National Energy Policy Commission (NEPC) has approved two FiTs programs, which resurrected the support of solar PV in Thailand. The FiTs contract duration of each project was set to 25 years.

The first FiTs program has included rooftop FiTs and community ground-mounted solar PV FiTs with a combined total target of 1,000 MW. The first FiTs program has been determined for rooftop solar PV with the rates for three scales of installations as shown in Table 1.

As shown in Table 1, the government has set a total quota of 200 
MW for rooftop solar PV FiTs with 100 MW allocated to residential scale installations $(0-10 \mathrm{~kW})$ and another $100 \mathrm{MW}$ allocated to commercial and industrial scale installations $(>10$ $1,000 \mathrm{~kW})$. The second FiTs program has been determined for community ground mounted solar (1 Tambon, $1 \mathrm{MW}$ ). This program had built-in degression in three steps, with the rate of 9.75 Thai Baht $/ \mathrm{kWh}$ for years 1-3, 6.50 Thai Baht $/ \mathrm{kWh}$ for years 4-10, and 4.50 Thai Baht $/ \mathrm{kWh}$ for years 11-25. The government has allocated a total quota of $800 \mathrm{MW}$ for this community FiTs program with the conditions that the systems must be installed by December 2014. However, the National Council for Peace an Order, which came into power in May 2014, had transformed the $800 \mathrm{MW}$ community programs into a program that would instead be sited on government properties and on the properties of agricultural co-operatives. This program has aimed at realizing solar farms up to $5 \mathrm{MW}$ in the form of public private partnerships with the governmental sector or agricultural cooperatives as public partners. Power has been purchased via a FiTs at a rate of 5.66 Thai Baht $/ \mathrm{kWh}$ for 25 years. The application process has been separated into 2 phases. Phase 1 has set a total target at 600 MW for regions with currently available transmission line capacity (North, East, West and Central). To fulfill the $800 \mathrm{MW}$ quota, phase 2 has set a target to $200 \mathrm{MW}$.

Current status: In phase 1 , the target has been initially planned for a total of $600 \mathrm{MW}$ with available transmission line capacity. However, ERC's re-announcement after NEPC's resolution [9] has revised phase 1 target down to $300 \mathrm{MW}$. Therefore, phase 1 has only contained the projects under agricultural cooperatives, 67 projects have been selected with a total of $281.32 \mathrm{MW}$. The projects must be commercially operated by $30^{\text {th }}$ December 2016 . For phase 2, ERC announced the target of 219 MW on 28 April 2017 (100 MW for projects with governmental agency and 119 MW for projects with agricultural cooperatives). Power has been purchased via a FiTs at a rate of 4.12 Thai Baht $/ \mathrm{kWh}$ for 25 years. The projects must be commercially operated until $30^{\text {th }}$ June 2018.

Finally, in January 2015, the National Reform Council (NRC) approved a program that aims simplifying the installation of rooftop solar PV and allows all citizens to install and connect it to the power network. The rooftop solar PV self-consumption pilot scheme shows the policy maker's intention to move away from the FiTs towards a self-consumption driven market. ERC officially announced the scheme on August 11, 2016. The systems must be installed by January 31,2017 . This scheme is positioned as a pilot scheme, meaning that governmental agencies want to use this scheme to first monitor and evaluate the data. The results from the evaluation and analysis by the consultant of the government will be presented as technical and policy suggestion towards the government in order to plan future support scheme for rooftop solar PV. However, amenity of the self-consumption scheme been low, only $38.38 \mathrm{MW}$ has been applied from the quota of $100 \mathrm{MW}$. Projects must have been connected to the network by $31^{\text {st }}$ January 2017.

A timeline for Thailand's solar target and policy is illustrated in Fig. 2. According to the Energy Regulatory Commission (ERC) latest information (28 February 2017), the total installed capacity of solar PV (already COD) in Thailand reached 2,979 MW. Out of which there were 2,845 MW of free-field installations (solar farms) and $130 \mathrm{MW}$ of solar rooftops as shown in Table 2.

\section{Barriers against Solar PV Support}

From the history of solar PV in Thailand, the barriers can be classified into three aspects consisting of policy, economics, and technique. The details of each aspect are explained below.

\subsection{Policy Barrier}

Policy uncertainties remain a key element of Thailand solar PV development. The adder support for solar PV that began in 2007 was interrupted in the three years during 2010-2013 and was followed by a brief opening of new support in the form of FiTs in the two months period between October-November 2013.

Table 2 Current status of solar PV program in Thailand [3]

\begin{tabular}{|c|c|c|c|c|c|}
\hline Type & Program & $\begin{array}{l}\text { COD } \\
\text { (MW) }\end{array}$ & $\begin{array}{c}\text { PPA } \\
\text { signed } \\
\text { but still } \\
\text { not } \\
\text { COD } \\
\text { (MW) }\end{array}$ & $\begin{array}{c}\text { COD } \\
\text { deadline }\end{array}$ & $\begin{array}{l}\text { Quota } \\
\text { (MW) }\end{array}$ \\
\hline \multirow{3}{*}{$\begin{array}{l}\text { Solar } \\
\text { farm }\end{array}$} & $\begin{array}{c}\text { Adder \& FiTs } \\
\text { scheme }(2006- \\
2015)\end{array}$ & 2,627 & - & Finished & 2,800 \\
\hline & $\begin{array}{c}\text { Governmental \& } \\
\text { Agricultural } \\
\text { Cooperatives } \\
\text { phase } 1\end{array}$ & 218 & 21 & Finished & \multirow{2}{*}{800} \\
\hline & $\begin{array}{c}\text { Governmental \& } \\
\text { Agricultural } \\
\text { Cooperatives } \\
\text { phase } 2 \\
\end{array}$ & - & - & $\begin{array}{c}30^{\text {th }} \text { June } \\
2018\end{array}$ & \\
\hline \multirow[b]{2}{*}{$\begin{array}{l}\text { Solar } \\
\text { rooftop }\end{array}$} & $\begin{array}{c}\text { Phase } 1(2013) \\
\& \text { Phase } 2 \\
(2015)\end{array}$ & 130 & - & Finished & 200 \\
\hline & $\begin{array}{c}\text { Self- } \\
\text { consumption } \\
\text { pilot scheme } \\
(2016) \\
\end{array}$ & - & 38 & Finished & 100 \\
\hline Total & & 2,975 & 59 & & 3,900 \\
\hline
\end{tabular}

Uncertainties and discontinuities in incentive scheme or financial support policies make project investment valuation difficult and severely limit investors' interest.

\subsection{Economics Barrier}

The high cost of solar PV remains one of the highest ranked barriers. This is especially true for small scale rooftop solar PV whose potential owners may not be able to afford the upfront cost. However, average cost of solar PV is continuously decreasing according to National Renewable Energy Laboratory (NREL) report. [10]

\subsection{Technical Barriers}

For the technical barriers which are the main focused barriers in this paper, the Adder program has driven the emergence of solar farms in many locations across the country, but there is an agglomeration of projects particularly in areas of high solar irradiation; for example, in the Northeast of Thailand. This physical clustering of supply may generate more power than demands.

Consequently, the power from solar PV will flow backwards to the higher-voltage network which can cause adverse impacts to the system; for example, system loss increasing, voltage violation, miscoordination of protective devices, etc. The solar PV impacts on the system can be summarized as shown below 
[11-13]

\subsubsection{Impact on Voltage}

Generally, without solar PV, electric utilities set the voltage operation of the substation and distribution transformers within the voltage standard range. However, when solar PV is installed into the system, the power from solar PV can affect voltage operation by causing voltage violation. For example, when solar PV installed around residential area generates high power at noon while the residential demand at this time is generally low. This causes the high voltage which may exceed the maximum voltage standard limit. Example of voltage problem for a high penetration of solar PV is shown in Fig. $3[14,15]$.

\subsubsection{Impact on System Loss}

In general, solar PV reduces system loss as it brings generation closer to the demand. This assumption is true until reverse power flow occurs. A study from [16] showed that distribution system loss reach a minimum value at a penetration level of approximately $5 \%$, but when the penetration level increases, the system loss also increase and may exceed the no-solar PV system case.

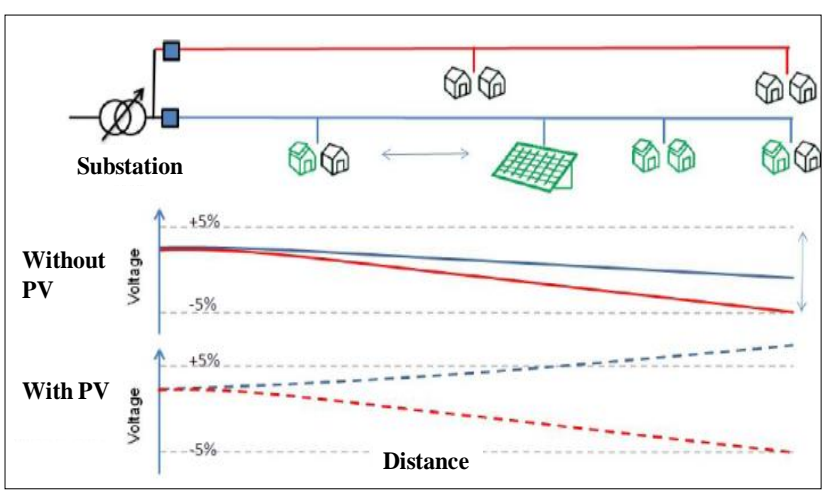

Fig. 3 Voltage problem for a high penetration of solar PV

\subsubsection{Impact on Peak Demand Forecast and Equipment Capability}

Because solar PV will generate high power during daytime which generally occurs peak demand in Thailand, some power demand is supplied by solar PV. Consequently, peak demand is likewise decreased. Without good information exchange between system planning operator and solar PV producers, error of demand forecast can be occurred. This error can consequently affect the power procurement planning and power system expansion planning as well. Moreover, the equipment in power system is generally not designed to support the coming of solar PV. Therefore, when high penetration of solar PV is installed into the system, the power from solar PV can violate some equipment capability which results to the equipment damage.

\subsubsection{Impact on Short Circuit Current}

When solar PV is installed into the system, the short circuit current will be increased because the short circuit current from solar PV will inject to the system as well. This total amount of short circuit current can be higher than the interrupting capacity of protective equipment, and cause the damage on it.

\subsubsection{Impact on Protective Equipment Operation}

Generally, operation scheme of protective equipment is designed without the existence of solar PV. When short circuit current occurs, the protective equipment will operate in order to limit the damage from the short circuit current. In case that solar PV is installed into the system, the short circuit current from solar PV can affect operation scheme of protective equipment and cause the miscoordination of protective equipment. Consequently, the protective equipment may unnecessarily operate and thus the power outage unnecessarily occurs.

\subsubsection{Islanding Situation}

In general, when short circuit current occurs, the transmitted power will be interrupted by the operation of protective equipment before solving the short circuit current in order to secure the safety during solving. However, if islanding occurrence is allowed, it means that the solar PV or other distributed generators can supply electricity to nearby customers while the power from utilities is interrupted. In this case, it is unsecure situation that the electricity exists during solving short circuit current.

\subsubsection{Impact on System Reliability}

Impact on system reliability is the subsequently resulted from impacts in 3.4.3, 3.4.4, and 3.4.5. This is to say, the error of peak forecasted demand, the increasing of short circuit current, and the miscoordination operation of protective equipment can increase the probability of power outage. This will result in the system reliability reduction.

Table 3 PEA Capacity Limitations

\begin{tabular}{|c|c|c|c|}
\hline & Low Voltage & \multicolumn{2}{|c|}{ Medium Voltage } \\
\cline { 3 - 4 } & $\mathbf{3 8 0 / 2 2 0} \mathbf{~ V}$ & $\mathbf{2 2} \mathbf{~ k V}$ & $\mathbf{3 3} \mathbf{~ k V}$ \\
\hline $\begin{array}{c}\text { Single Phase } \\
\text { Power } \\
\text { Capacity }\end{array}$ & $\begin{array}{c}\leq 5 \mathrm{~kW} \text { per } 1 \\
\text { power producer }\end{array}$ & \multicolumn{2}{|c|}{} \\
\hline Transformer & $\begin{array}{c}\text { Total capacity of } \\
\text { all power } \\
\text { Capacity }\end{array}$ & $\begin{array}{c}\text { poducers } \leq 15 \% \\
\text { of transformer } \\
\text { capacity (kVA) }\end{array}$ & $\begin{array}{c}\text { Total capacity of all power } \\
\text { producers for all feeders } \leq 75 \% \\
\text { of transformer capacity (MVA) }\end{array}$ \\
\hline Feeder & - & $\begin{array}{c}\text { Total capacity } \\
\text { of power } \\
\text { Capacity }\end{array}$ & $\begin{array}{c}\text { Total capacity } \\
\text { of power } \\
\text { feeder } \leq 8 \\
\text { producers per } \\
\text { feeder } \leq 10 \\
\text { MW }\end{array}$ \\
\hline
\end{tabular}

Table 4 MEA Capacity Limitations

\begin{tabular}{|c|c|c|c|}
\hline & \multirow{2}{*}{$\begin{array}{c}\text { Low Voltage } \\
400 / 230 \mathrm{~V} \\
\end{array}$} & \multicolumn{2}{|c|}{ Medium Voltage } \\
\hline & & $12 \mathrm{kV}$ & $24 \mathrm{kV}$ \\
\hline $\begin{array}{l}\text { Single Phase } \\
\text { Power } \\
\text { Capacity }\end{array}$ & $\begin{array}{c}\leq 5 \mathrm{~kW} \text { per } 1 \\
\text { power producer }\end{array}$ & \multicolumn{2}{|c|}{ - } \\
\hline $\begin{array}{c}\text { Transformer } \\
\text { Capacity }\end{array}$ & $\begin{array}{l}\text { Total capacity of } \\
\text { all power } \\
\text { producers } \leq 15 \% \\
\text { of transformer } \\
\text { capacity (kVA) }\end{array}$ & \multicolumn{2}{|c|}{$\begin{array}{c}\text { Total capacity of all power } \\
\text { producers for all feeders } \leq 20 \% \\
\text { of transformer capacity (MVA) }\end{array}$} \\
\hline $\begin{array}{l}\text { Feeder } \\
\text { Capacity }\end{array}$ & - & $\begin{array}{l}\text { Total capacity } \\
\text { of power } \\
\text { producers per } \\
\text { feeder } \leq 4 \\
\text { MW }\end{array}$ & $\begin{array}{c}\text { Total capacity } \\
\text { of power } \\
\text { producers per } \\
\text { feeder } \leq 8 \\
\text { MW }\end{array}$ \\
\hline
\end{tabular}

From the analysis of the above impacts, it is found that the impacts on voltage, system loss, and peak demand forecast and 
equipment capability are very significant because these impacts directly influence to security, reliability, quality of supply, utility incomes, and utility investment cost.

\section{Present Solutions for Solving Technical Barriers}

At present, the electric utilities try to solve the technical barriers by using two methods. The first is limiting the capacity of solar $\mathrm{PV}$. The second is installing equipment to solve the problems from solar PV. The details of each solution are explained below.

\subsection{Limiting Capacity of Solar PV}

In order to avoid the problems as mentioned in Subsection 3.3, electric utilities Provincial Electricity Authority (PEA) and Metropolitan Electricity Authority (MEA) determine the capacity limitation criteria for power producer (including solar PV) into their grid codes $[17,18]$ as shown in Table 3 and Table 4, respectively.

As mentioned in Subsection 3.3, the impacts of solar PV depend on installation location. However, from the above limitation criteria of both utilities, the criteria are determined without consideration of solar PV location. If solar PV in that feeder is installed at a proper location, that feeder may support more amount of solar PV than the amount determined in utility grid code. Therefore, the proposed method for supporting solar PV in this paper considers the location of solar PV which will be explained later in Section 5.

\subsection{Equipment Installation}

According to Subsection 3.3, the utilities may solve the problems by installing equipment in their systems. For example, Static VAR Compensator (SVC) and Automatic Voltage Regulator (AVR) are utilized to control voltage within the standard range. Information exchange system between utilities and power producers is used to support the system planning, operation and management of the utilities. Note that the equipment installation can be invested by both utilities side and solar PV producer side.

\section{Proposed Method for Supporting Solar PV}

From Subsection 4.1, although the limiting capacity criteria of solar PV can solve the technical barriers, it obstructs the coming of solar PV. Consequently, the growth of solar PV cannot increase as expected. Therefore, this paper proposes the method to maximize the coming of solar PV by increasing the capacity limitation of power producers.

In fact, the distribution utilities determine the limit of feeder capacity in their grid code as shown in table 3 and 4 by using average value of the minimum demand of all feeders. From the explanation of distribution utilities, when power producer capacity is higher than demand, there is an opportunity to occur the reverse power flow coming from the power producers. This phenomenon causes voltage violation, increasing system loss, and miscoordination of protection scheme. That is the reason why distribution utilities determine the capacity limitation of power producers which is not higher than average value of the minimum demand of all feeders.

Actually, the location of power producers in a feeder can affect to voltage, system loss, and operation of protection equipment. These may cause the higher or lesser capability of the system to support coming of power producers. However, the locations of power producers in a feeder are not taken into account before defining the capacity limitation criteria. Therefore, this paper proposes the method to maximize the level of solar PV by considering the installed locations in feeder of solar PV when determining the capacity limitation criteria. The installed locations of solar PV are classified into three scenarios: clustered around the beginning of feeder, clustered around the midpoint of feeder, and clustered around the end of feeder as shown in Fig 4. From Fig. 4, the process for calculating the maximum capacity of solar PV for each scenario is proposed. The considered constraints are voltage and system loss. For voltage constraint, the voltage of each bus must operate within the standard range. For system loss, the system loss after installing solar PV must not higher than system loss of the system before installing solar PV. The objective function and constraints are written as shown in Equations (1)-(4).

Objective function:

$\operatorname{Maximize}\left(S_{\text {Solar_cap }_{-}}\right)$

Subject to:

$V_{P C C_{-} B f} \geq V_{P C C_{-} A f}$

$V_{i}^{\min } \leq V_{i} \leq V_{i}^{\max }, \quad i \in \Omega^{b}, \quad i=1, \ldots, n b$

$P_{\text {Loss }_{-} A f} \leq P_{\text {Loss }_{-} B f}$

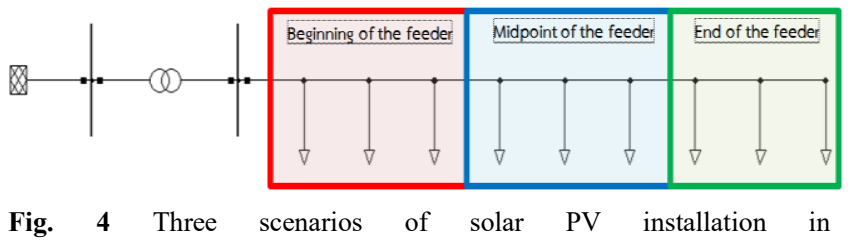

distribution system 


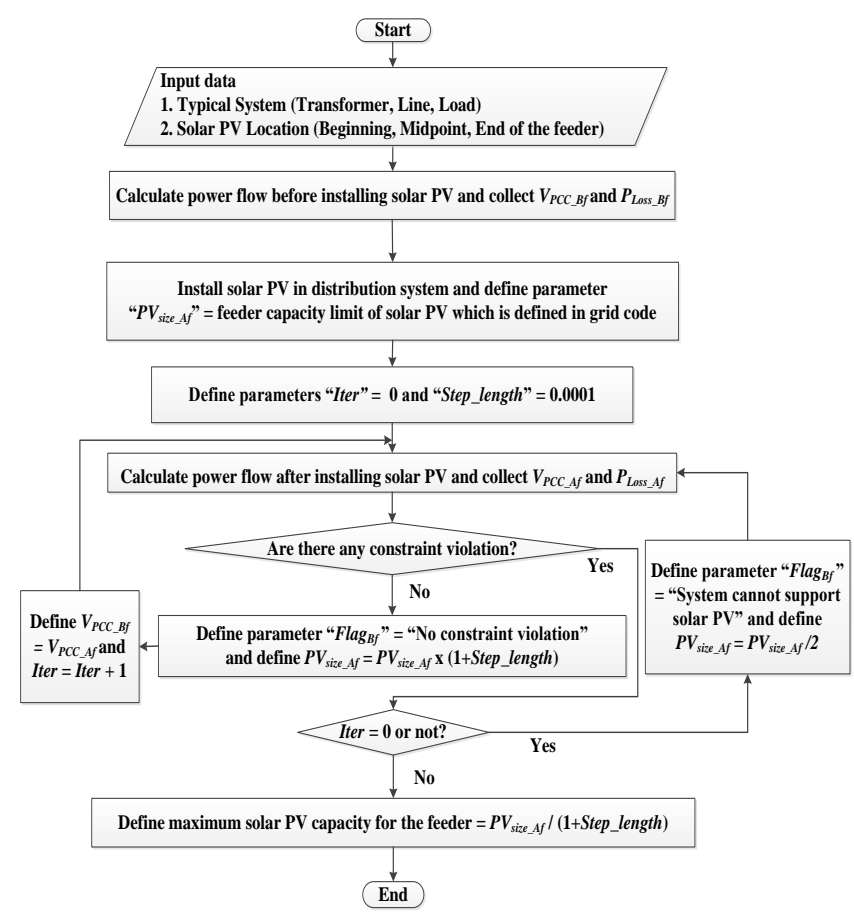

Fig. 5 The procedure of the proposed method to calculate the maximum capacity of solar PV

where,

Solar_cap is solar PV installed capacity (MW)

$i \quad$ is index of bus

$V_{P C C_{-} B f} \quad$ is voltage magnitude at connecting point before installing solar PV (V)

$V_{P C C_{-} A f} \quad$ is voltage magnitude at connecting point after installing solar PV (V)

$V_{i} \quad$ is voltage at bus $i(\mathrm{~V})$

$V_{i}^{\text {min }} \quad$ is minimum limit of voltage at bus $i(\mathrm{~V})$

$V_{i}^{\max } \quad$ is maximum limit of voltage at bus $i(\mathrm{~V})$

$\Omega^{b} \quad$ is the set of buses in the system

$n b \quad$ is the number of bus in the system

$P_{\text {Loss_Af }} \quad$ is power system loss after installing solar PV (MW)

$P_{\text {Loss_Bf }} \quad$ is power system loss before installing solar PV (MW)

The procedure of the proposed method to calculate the maximum capacity of solar PV for each scenario can be explained as shown in Fig. 5.

\section{Numerical Results and Discussion}

In this section, the proposed method for supporting solar PV is tested on the modified typical distribution system in Thailand. The method runs on an Intel Core i7 2.7-GHz processor based computer. All programs are written on DIgSILENT Programming Language (DPL) in the DIgSILENT PowerFactory version 15.1. In order to understand the distribution system in Thailand, the modified typical distribution system in Thailand is presented in Subsection 6.1. The simulation cases and the obtained results are described in Subsection 6.2. Finally, the discussion on test results is presented in Subsection 6.3.

\subsection{The Modified Typical Distribution System in Thailand}

The schematics of both PEA and MEA distribution systems are radial. The system consists of one transformer installed at the beginning of feeder and at least one feeder connected between the

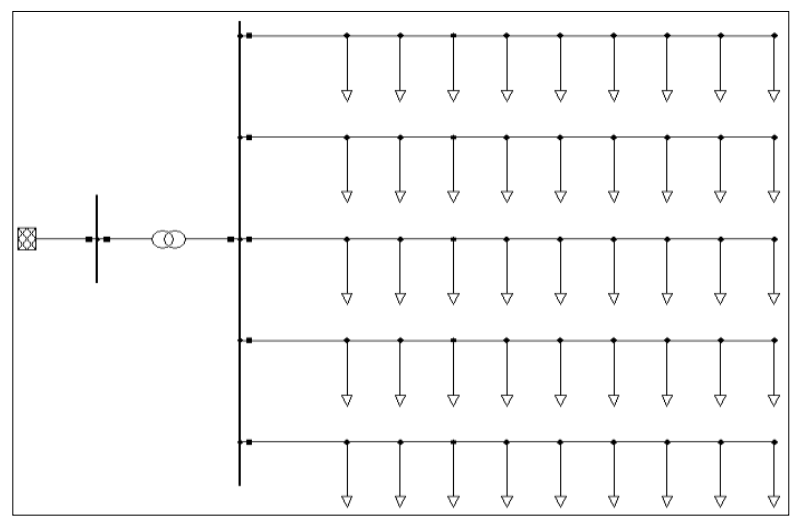

Fig. 6 Medium voltage distribution system in Thailand

Table 5 Data of medium voltage transformer

\begin{tabular}{|c|c|c|c|c|c|c|}
\hline \multirow{2}{*}{$\begin{array}{c}\text { Utilit } \\
\mathrm{y}\end{array}$} & \multirow{2}{*}{$\begin{array}{c}\text { Capacit } \\
\text { y } \\
\text { (MVA) }\end{array}$} & \multirow{2}{*}{$\begin{array}{c}\text { Utilizatio } \\
\mathrm{n} \text { factor } \\
(\%)\end{array}$} & \multicolumn{2}{|c|}{$\begin{array}{l}\text { Transformer } \\
\text { parameters }\end{array}$} & \multirow{2}{*}{$\begin{array}{l}\text { Voltag } \\
\text { e } \\
\text { range } \\
\text { (p.u.) }\end{array}$} & \multirow{2}{*}{$\begin{array}{l}\text { Voltag } \\
\text { e } \\
\text { setpoin } \\
\text { t (p.u.) }\end{array}$} \\
\hline & & & $\begin{array}{c}\mathrm{R} \\
\text { (p.u.) }\end{array}$ & X(p.u.) & & \\
\hline MEA & 60 & 75 & $\begin{array}{c}0.0039 \\
3 \\
\end{array}$ & $\begin{array}{c}0.2000 \\
0\end{array}$ & $\begin{array}{c}0.91- \\
0.98\end{array}$ & 0.96 \\
\hline PEA & 50 & 75 & $\begin{array}{c}0.0030 \\
0\end{array}$ & $\begin{array}{c}0.1499 \\
7\end{array}$ & $\begin{array}{l}0.95- \\
1.05\end{array}$ & 1.00 \\
\hline
\end{tabular}

Table 6 Data of medium voltage distribution line

\begin{tabular}{|c|c|c|c|c|c|c|}
\hline \multirow[b]{2}{*}{$\begin{array}{c}\text { Utilit } \\
\mathrm{y}\end{array}$} & \multirow[b]{2}{*}{$\begin{array}{c}\text { Lengt } \\
\mathrm{h} \\
(\mathrm{km})\end{array}$} & \multirow[b]{2}{*}{$\begin{array}{l}\text { Curre } \\
\text { nt } \\
\text { rating } \\
(\mathrm{kA})\end{array}$} & \multirow[b]{2}{*}{$\begin{array}{l}\text { Average } \\
\text { minimum } \\
\text { demand }\end{array}$} & \multirow{2}{*}{$\begin{array}{c}\text { Distance } \\
\text { between } \\
\text { transform } \\
\text { er and the } \\
\text { nearest } \\
\text { customer } \\
(\mathrm{km})\end{array}$} & \multicolumn{2}{|c|}{ Line parameters } \\
\hline & & & & & $\begin{array}{c}\mathrm{R} \\
\text { (p.u.) }\end{array}$ & $\begin{array}{c}\text { X(p.u. } \\
\text { ) }\end{array}$ \\
\hline MEA & 8.371 & 0.390 & $\begin{array}{c}20 \% \text { of } \\
\text { transform } \\
\text { er } \\
\text { capacity }\end{array}$ & 0.735 & $\begin{array}{c}0.2000 \\
0\end{array}$ & $\begin{array}{c}0.2950 \\
0\end{array}$ \\
\hline PEA & 46.60 & 0.429 & $\begin{array}{c}20 \% \text { of } \\
\text { transform } \\
\text { er } \\
\text { capacity }\end{array}$ & 0.500 & $\begin{array}{c}0.2106 \\
5\end{array}$ & $\begin{array}{c}0.4114 \\
0\end{array}$ \\
\hline
\end{tabular}

transformer and customers in order to distribute power to customers. In this paper, the medium voltage distribution system is applied for testing as shown in Fig. 6.

From Fig. 6, the power flow is unidirectional from the transformer to customers. Nevertheless, when solar PV is installed at any feeder in the system, the power from solar PV may reverse into the transformer (bidirectional power flow). This situation can contribute the impact to the system both voltage and system loss. For PEA and MEA distribution systems, there are some differences such as voltage level, transformer capacity, and length of distribution line. The data of system components are shown in Table 5 and 6.

The test system in this paper consists of 5 feeders and there are 9 load points for each feeder as shown in Fig. 6. The distances between any two load points are determined. Similarly, the demands of each load point are equally determined as well, and the summation of all loads must equal to $20 \%$ of transformer capacity (as determined in grid code, Table 4). 


\subsection{Test and Results}

The test is divided into two cases composing of all solar PVs clustered at one area of feeder and distributed along feeder. The methods for testing and results are explained below.

\subsubsection{Testing Method for All Solar PVs Clustered at One Area of Feeder}

The testing method for this case can be explained as shown below.

1) Install solar PV around the end of feeder.

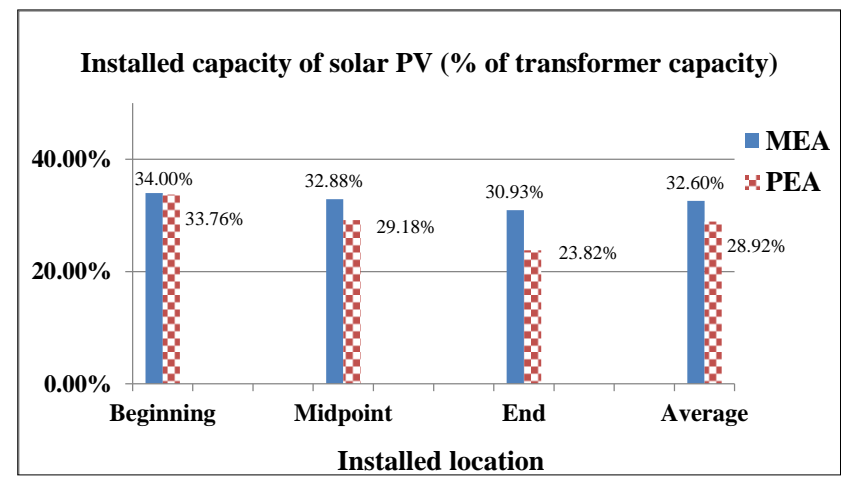

Fig. 7 Installed capacity of solar PV in the case all solar PVs clustered at one area of feeder

Note: The transformer capacities of MEA and PEA are 60 MVA and 50 MVA, respectively.

2) Calculate and collect the maximum installed capacity of solar PV that satisfies voltage and system loss criteria as shown in Fig 5 .

3) Change the location of solar PV to the midpoint of feeder. After that, calculate and collect the maximum installed capacity of solar PV same as 2).

4) Change the location of solar PV to the beginning of feeder. After that, calculate and collect the maximum installed capacity of solar PV same as 2).

5) Calculate the average values of three maximum installed capacities obtained from the three cases of installed location.

The results of maximum installed capacity of solar PV that satisfies voltage and system loss criteria are shown in Fig. 7.

From the above results of MEA, it can be observed that, installed capacities of solar PV of all three cases, the beginning, midpoint, and end of feeder, are higher than the MEA capacity limitation in grid code (Table 4 ) which is $20 \%$ of transformer capacity. From the results of PEA, it is found that the installed capacities of solar PV of all three cases, the beginning, midpoint, and end of feeder, are less than the PEA capacity limitation in grid code (Table 3) which is $75 \%$ of transformer capacity. Moreover, it can be observed from Fig. 7 that the installed capacities of solar PV at the beginning of feeder for both MEA and PEA are the highest while the installed capacities of solar PV at the end of feeder are the lowest. These results can be indicated that the location near transformer can support more solar PV than the farther location when considering voltage and system loss criteria.

\subsubsection{Testing Method for Distributed Locating all Solar PVs along Feeder}

Generally, it is difficult that all power producers will install all solar PVs at the same or nearby location along feeder because there is no regulation to force them to install solar PV at predetermined locations. Therefore, solar PVs in real situation are distributed along feeder. In this case of testing, the allocation of solar PV capacity along feeder is determined based on the maximum installed capacity of each location obtained from the test in Subsection 6.2.1.

The testing method for this case can be explained as shown below.

1) Install solar PV around the end, midpoint, and beginning of feeder simultaneously according to the maximum installed capacity of each location obtained from the test in Subsection 6.2.1.

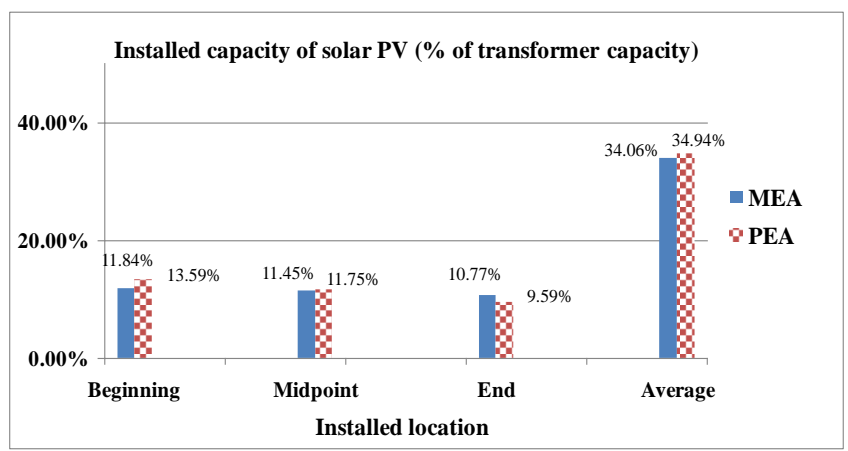

Fig. 8 Installed capacity of solar PV in the case of distributed locating all solar PVs along feeder

Note: The transformer capacities of MEA and PEA are 60 MVA and 50 MVA, respectively.

2) Calculate and collect the maximum installed capacity of solar PV that satisfies voltage and system loss criteria as shown in Fig 5.

3) Calculate the summation values of three maximum installed capacities of each location.

The results of maximum installed capacity of solar PV that satisfy voltage and system loss criteria are shown in Fig. 8. From Fig. 8, it can be observed that, the total installed capacities of solar PV are $34.06 \%$ and $34.93 \%$ for MEA and PEA, respectively. Same as the case of all solar PVs are clustered at one area of feeder, the solar PV installed capacity of MEA is higher than the capacity limitation in the MEA grid code and the solar PV installed capacity of PEA is lower than the capacity limitation in the PEA grid code.

In order to identify the method that can support more solar PV, the capability for supporting solar PV of both methods are compared as presented in Fig. 9 and Fig. 10 for MEA and PEA, respectively. From Fig. 9 and Fig. 10, considering at the "average/total" column, it can be seen that the total installed capacity of solar PV in the case of distributed locating all solar PVs along feeder is higher than the average installed capacity of solar PV in the case of all solar PVs clustered at one area of feeder. Moreover, the total installed capacity of solar PV in the case of distributed locating all solar PVs along feeder is higher than the installed capacity of solar PV in the case of all solar PVs clustered at the beginning of feeder which is the best solution in this case. These can be interpreted that distributed locating all solar PVs along feeder can support more solar PV than all solar PVs clustered at one area of feeder. 


\subsection{Discussion on Test Results}

From the test results above, distributed locating all solar PVs along feeder can support more solar PV than all solar PVs clustered at one area of feeder. Consequently, in order to maximize solar PV, distributed locating all solar PVs along feeder is suggested for distribution utilities to determine the location and capacity of solar PV.

Considering the capacity limitation in grid code, for MEA, the installed capacities of solar PV from the testing in Subsections 6.2.1 and 6.2.2 are higher than the capacity limitation in the MEA grid code. This is because MEA determines this capacity limitation to avoid the reverse power flow which may cause voltage violation and system loss increase. During the test, it is observed that a few reverse power flow does not cause any voltage violation and system loss increase.

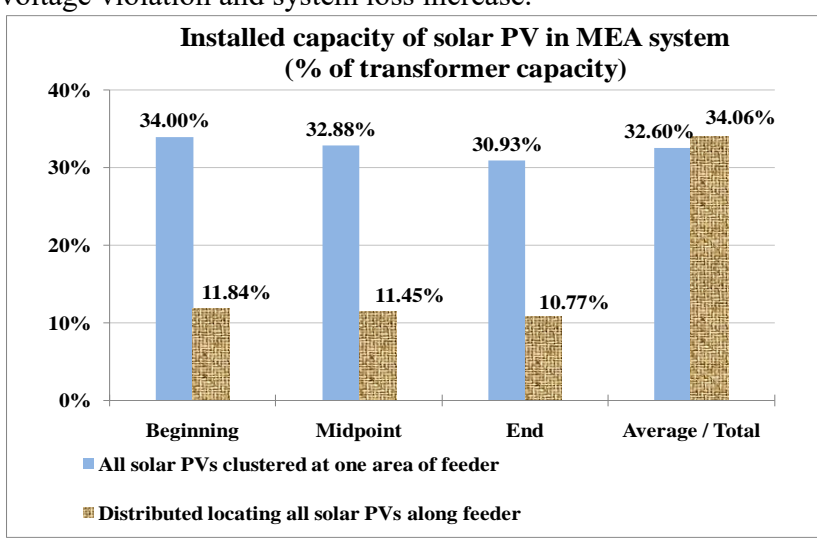

Fig. 9 Comparison between all solar PVs clustered at one area of feeder and distributed locating all solar PVs along feeder for MEA system

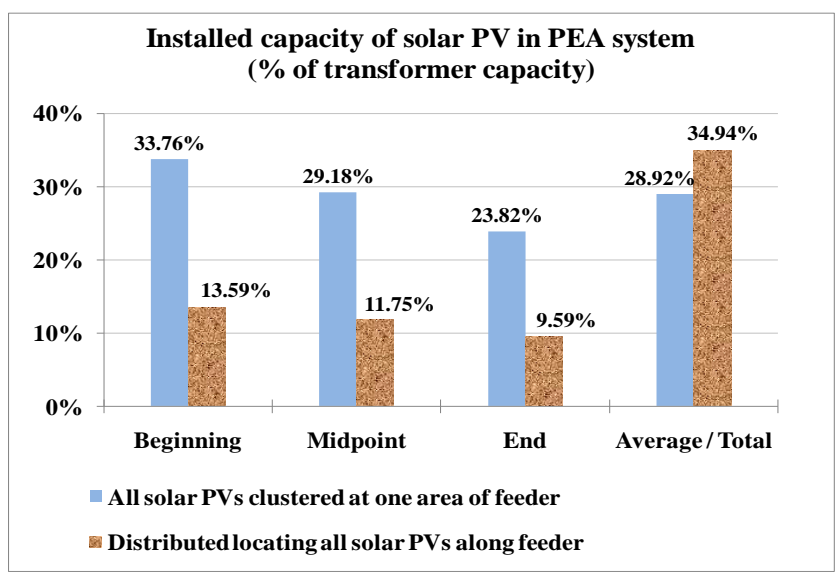

Fig. 10 Comparison between all solar PVs clustered at one area of feeder and distributed locating all solar PVs along feeder for PEA system

Therefore, the installed capacities of solar PV are higher than $20 \%$ of transformer capacity which is determined in the MEA grid code. For PEA, it is found that installed capacities of solar PV in Subsections 6.2.1 and 6.2.2 are less than the PEA capacity limitation in grid code which is $75 \%$ of transformer capacity. It can be said that, this capacity limit in the PEA grid code is too high because the maximum installed capacity of solar PV from the test result is only $34.94 \%$ of transformer capacity. Therefore, if PEA allows power producers to install solar PV in feeder higher than $34.94 \%$ of transformer capacity, it will cause voltage violation and system loss increase. Consequently, PEA may reduce the capacity limitation in grid code according to the results from this paper cooperating with PEA analysis.

\section{Conclusion}

Solar PV history in Thailand consisting of target, incentive schemes, procurements and barriers for supporting the coming of solar PV is presented. One of the most significant barriers is the technical power system problem; for example, voltage violation and system loss. Consequently, the method to solve technical barriers in order to maximize the level of solar PV is proposed. The method is based on the classification of typical distribution feeders with various levels of solar PV penetration and location. The results show that, when all solar PVs are clustered at one area of feeder, all solar PVs clustered at the beginning of feeder can support more solar PV than the farther location. However, distributed locating all solar PVs along feeder can support more solar PV than all solar PVs clustered at one area of feeder. For the viewpoint of capacity limitation in grid code, the test results from the MEA system show that the system can support more solar PV than the capacity limitation determined in the MEA grid code. For the PEA system, the test results show that the capacity limitation determined in the PEA grid code is higher than the obtained results. Therefore, according to the results from this paper cooperating with MEA/PEA analysis, MEA may extend the capacity limitation in order to support more solar PV and PEA may reduce the capacity limitation in order to avoid voltage violation and system loss increase

\section{Acknowledgement}

This research is supported by Rachadapisek Sompote Fund for Postdoctoral Fellowship, Chulalongkorn University and by National Research University Project, Office of Higher Education Commission (NRU59-050-EN).

\section{References}

[1] EGAT, Electricity Generating Authority of Thailand. Available from: URL: http://www.egat.co.th/index.php?option=com_content\&view=artic le\&id=2068:fuel-consumption-2560\&catid=39\&Itemid=116

[2] Alternative Energy Development Plan 2015. Department of Renewable Energy Development and Energy Efficiency, Thailand; 2015.

[3] ERC, Energy Regulatory Commission, Thailand. Available from: URL:

http://www.erc.or.th/ERCSPP/default.aspx? $=0$ \&muid=23\&prid= 41

[4] Umid M. The Impacts of Increased Distributed Solar PV Penetration on Distribution Network - Review. Oregon: Oregon Institute of Technology; 2015.

[5] Zetty A., Azah M., and Hussain S. "Effect of grid-connected photovoltaic systems on static and dynamic voltage stability with analysis techniques - a review”, PRZEGLĄD ELEKTROTECHNICZNY, (2015).

[6] Mesut E. B., Hossein H., Zhan S., and Alex H.: "Accommodating High PV Penetration on Distribution Feeders", IEEE Transactions on Smart Grid., Vol. 3, Issue: 2, (2012).

[7] Annual Report 2016, Energy Policy and Planning Office, 
Thailand; 2016

[8] DEDE, Department of Renewable Energy Development and Energy Efficiency, Thailand. Available from: URL: http://www.dede.go.th/ewt_news.php?nid=42079

[9] National Energy Policy Commission Resolution, Thailand. Available from: URL:http://www.eppo.go.th/index.php/th/menuconclufilter?orders[publishUp] $=$ publishUp\&issearch=1

[10] Ran F., Donald C., Travis L., David F., Kristen A., and Robert M. "U.S. Solar Photovoltaic System Cost Benchmark: Q1 2016". National Renewable Energy Laboratory. 2016.

[11] The Study of Solar PV Effect on Metropolitan Electricity Authority System and Determination of Support Measure Progress Report. Power System Research Laboratory, Department of Electrical Engineering, Chulalongkorn University, Thailand. 2016.

[12] El K., W., and Salama M. M. A., "Impact of Distributed Generation on Voltage Profile in Deregulated Distribution System Key Terms" pp. 3-8, Proceedings of the Power Systems 2002 Conference, Impact of Distributed Generation, Clemson, SC, USA. 2002.

[13] David M. T. "A Review on Impacts of Grid-Connected PV System on Distribution Networks" International Journal of Electrical, Computer, Energetic, Electronic and Communication Engineering, Vol. 10, No: 1, (2016).

[14] Balamurugana K., and Dipti S., and Thomas R. "Impact of Distributed Generation on Power Distribution Systems". Energy Procedia 25. (2012).

[15] Updating Interconnection Screens for PV System Integration. National Renewable Energy Laboratory. 2012.

[16] Miller N., and Ye Z., "Report on Distributed Generation Penetration Study", National Renewable Energy Laboratory. 2013.

[17] The Grid Code of Metropolitan Electricity Authority. 2015. Available from: URL:http://www.mea.or.th/upload/download/file_a10ffd98094063 f94aaddb32995d505f.pdf

[18] The Grid Code of Provincial Electricity Authority. 2016. Available from:

URL:https://www.pea.co.th/Portals/0/Document/connection_code _2016_20170928.pdf 